\title{
Pursuing the Promise of Preschool: An Exploratory Investigation of the Perceptions of Parents Experiencing Homelessness
}

\author{
Travis Wright $^{1}\left[\right.$ C Chase Ochrach ${ }^{1} \cdot$ Madison Blaydes $^{1} \cdot$ Anna Fetter $^{1}$
}

Published online: 24 September 2020

(c) Springer Nature B.V. 2020

\begin{abstract}
Rates of homelessness are worsening in the United States, with a third of individuals experiencing homelessness being families with children. These families face many challenges, including limited social supports, insufficient access to services, and mental health concerns. These challenges inform a nuanced worldview, leading parents experiencing homelessness to understand their child's school life in unique ways. The purpose of this study is to explore how parents experiencing homelessness understand their children's participation in Head Start and publicly funded $4 \mathrm{~K}$ programs. We utilized semi-structured interviews with parents of $4 \mathrm{~K}$ students and applied an iterative approach for analysis to identify emergent themes and concepts. Results suggest families enter homelessness through several avenues and struggle with many aspects of homelessness, including stigma directed at parents and children. Parents identified many strengths in their children's school programs, including education and support from faculty, as well as areas for growth, such as more comprehensive transportation and meal services. Overall, these results suggest families experiencing homelessness encounter many barriers to finding stable housing. Additionally, parents of children experiencing homelessness value their child's education and access to resources in schools while still fearing the potential for their child to experience stigmatization and discrimination in schools.
\end{abstract}

Keywords Early childhood education $\cdot$ Homelessness $\cdot$ Parents $\cdot$ Family engagement $\cdot$ Stigma

\section{Introduction}

Homelessness is a large-scale issue in the United States; in 2018, 552,830 individuals experienced homelessness on a given night (National Alliance to End Homelessness 2019). Since 2017, the number of people experiencing homelessness ${ }^{1}$ increased by 0.3 percent (National Alliance to End Homelessness 2019). Almost 33\% of individuals

\footnotetext{
1 We prefer to use person-first language in referencing individuals who are experiencing homelessness, recognizing that homelessness is an experience and not an identity. However, for clarity and space limitations we sometimes use the conventional term "homeless individuals", and the like, interchangeably.
}

This work was supported by a grant from the Madison Education Partnership at the University of Wisconsin-Madison, the Wisconsin Center for Educational Research, and the Madison Metropolitan School District.

Travis Wright

Travis.wright@wisc.edu

1 Department of Counseling Psychology, University of Wisconsin- Madison, 335 Education Building, 1000 Bascom Hall, Madison, WI 53706-1326, USA experiencing homelessness are families with children (U.S. Department of Housing and Urban Development 2018). In the 2017 to 2018 academic year, a reported 1.5 million children in public schools experienced homelessness, which is the highest number of students in more than a dozen years (Zaveri 2020). Many families with children live doubled-up with friends and family (4.4 million people in 2017), and $76 \%$ of public-school students experiencing homelessness lived in doubled-up arrangements in 2014-2015 (Children's Defense Fund 2017).

Unfortunately, the number of families with children experiencing homelessness is likely to rise as financial strain and instability is exacerbated by COVID-19. As of 2020, 10.9 million households in the United States spent $50 \%$ of their income on housing, which places them in a vulnerable position entering an economic crisis like this pandemic (Joint Center for Housing Studies 2020). Any change in employment could lead to homelessness, and as of April 2020, 22 million Americans have already filed for unemployment (Long and Van Dam 2020). This suggests homelessness in the United States is already a wide-scale issue that is likely to worsen in upcoming years, placing even more children 
and families in vulnerable positions. In addition to the pervasive impact of homelessness for children and families, these numbers also indicate that the sheer scale of this issue demands urgent attention and resources.

Demographically, most adults in families experiencing homelessness are between the ages of 18 and 30 and more than $77 \%$ of these adults are women (United States Interagency Council on Homelessness 2018). Of the children that are experiencing homelessness, about $45 \%$ of them are fiveyears-old or younger, making young children a substantial portion of the homeless population (Child Trends 2019.) About one third of children experiencing homelessness or highly mobile housing situations had a parent that had been incarcerated at some point in their lives (Casey, Shlafer, and Masten 2015). Racial and ethnic minorities made up a disproportionate percentage of families experiencing homelessness in 2016 with over 78.3\% non-White or White and Hispanic (United States Interagency Council on Homelessness 2018). These demographics suggest families experiencing homelessness often hold multiple marginalized identities, which places these parents and children in vulnerable positions, both socially and financially.

\section{The Impacts of Homelessness}

For children, homelessness is associated with risk across most, if not all, of the major developmental domains (Bassuk 2010; Buckner 2008; Miller 2011). Children experiencing homelessness are sick four times more often than children with stable housing (Weinreb et al. 1998). One out of every six children experiencing homelessness is diagnosed with emotional disturbances - compared to one out of every 12 housed children (Bassuk et al. 2015). In general, children navigating homelessness have lower attendance and are more likely to repeat a grade or drop out of school (Fantuzzo et al. 2013; Rouse et al. 2011). These risks are even more severe for children who face homelessness at a young age, which is more strongly related to lower mathematics achievement and reduced academic engagement than homelessness that occurs later in life (Fantuzzo et al. 2013).

Because children navigating homelessness often grow up in the context of conflict, social isolation, and limited resources, their experiences in school often reflect their struggle to adapt to new, unfamiliar contexts (Masten 2012; Wright 2007, 2014). Thus, it is not unexpected that homeless children's transitions to formal school settings are marked by insecure attachments and conflictual patterns of relationships (Anooshian 2005; Wright 2010). However, despite oftentimes overwhelming circumstances, some children experiencing homelessness show evidence of relatively positive adjustment (Cutuli et al. 2013; Herbers et al. 2011; Miller 2011). Given that some children do demonstrate competence despite adversity, it seems that there are opportunities for intervening experiences to support positive shifts in their developmental trajectories. Better understanding the processes underscoring such resilient functioning is critical to strengthening the field of child homelessness research.

\section{Supporting Parents Experiencing Homelessness: Unique Challenges}

Families with children experiencing homelessness face unique challenges, such as limited social networks, difficulties navigating services, and strained parent-child relationships (Wright 2018). Homeless families are often socially isolated, with few social supports or family networks upon which to rely (Dail 1990). When asked about social supports, Bassuk et al. (1996) found around 25\% of mothers experiencing homelessness were not able to name any. Of the mothers that could identify supports, about $18 \%$ identified only one person, of which $25 \%$ were their adult or dependent children. In addition, there are a number of systemic supports available to families experiencing homelessness, however these can be cumbersome or difficult to maneuver. Shelters can have adverse conditions, such as over-crowding and requirements for stay that can pose additional stressors for homeless parents (Kilmer et al. 2012). Homeless mothers must also tackle complex webs of services to access resources like employment, job training, health care, and education. Additionally, parents experiencing homelessness often dedicate significant energy to navigating systems, which can limit their time to invest in relationships with their children and impact their mental health. They may "expend tremendous emotional resources trying to meet basic human needs, often leaving little in reserve to offer support and understanding to their young children at a time when their children need it most" (Kelly et al. 2000). Mothers experiencing homelessness often demonstrate higher rates of major depression and higher rates of substance use, which are known risk factors for child abuse and neglect (Cowal et al. 2002). Major depressive disorder also can contribute to diminished sensitivity and responsiveness to infants' cues. Overall, these factors can negatively impact parent-child relationships (Cowal et al. 2002).

Though the Pre-K environment, given its structure and the opportunity to interact with non-parental adults and peers, seems a potential buffer for the negative effects of homelessness, there are barriers in these educational settings that can inhibit the growth and benefits of the programs for homeless children. Powers-Costello and Swick (2008) identified school cultural norms that often reflect negatively on homeless youth. Schools tend to prioritize desired attributes, such as school attendance and participation in school functions, which might not fit the experiences of homeless families and children and create a disconnect with the school culture (Delpit 1995; Stronge and 
Reed-Victor 2000). When these social norms and desirable attributes are left unchecked, it can lead teachers to hold negative attitudes towards homeless families and children. For example, Wright et al. (2019) found that pre-service teachers hold negative stereotypes about children and families experiencing homelessness. However, when educators learn more about the experiences of homeless families and youth, it can help them better understand these individuals' contexts and develop empathy (Powers-Costello and Swick 2008; Wright 2010).

Although the negative impacts of homelessness for children and families and the related educational barriers have been well-documented, researchers interested in promoting resilience among young children experiencing homelessness have relatively neglected the preschool setting. However, given its structure and the opportunity to interact with non-parental adults and peers, the preschool environment seems a potential buffer for the negative effects of homelessness. Indeed, newly emerging research is promising. Wright et al. (2017) found that children who are homeless or highly mobile and that attend community-based $4 \mathrm{~K}$ perform better in math and language arts in second grade than homeless or highly mobile students that did not attend these programs. Therefore, because of its potentially influential role, further studies are needed to examine the influence of Pre-K on the resilience of young children and their families experiencing homelessness.

In the present study, we seek to address this critical research gap by documenting how parents experiencing homelessness make meaning of preschool and experience their child and family's involvement in preschool programming. This is important because, even though research has consistently demonstrated that parental attitudes are essential influences in young children's participation in and attitudes about early childhood education (Yang and Shin 2008), virtually no work has examined how homeless families make meaning of their involvement. As families experiencing homelessness are among the most vulnerable, most underserved, and often the most difficult to support, better understanding parent perspectives is critical to strengthening efforts to support them.

\section{Conceptual Framework: Understanding Parents as Resources}

Historically, parents experiencing homelessness have either been viewed as passive, targeted recipients of services or as barriers to their children's educational pursuits (Wright $2010,2013,2018)$. In the worst of cases, parents experiencing homelessness are conceptualized as the barrier to their child's access to and attitude towards education, rather than as a potential resource and ally (Wright et al. 2019). However, in the current study we draw on a conceptual frame that places parents at the center of their children's educational lives and goals (Chavkin and Williams 1989). Previous findings suggest parents may play an unequivocal role in their children's approach toward education and the attitudes children hold towards learning (Cotton and Wikelund 1989; Swick 2009). Given the complexity faced by children experiencing homelessness in their everyday lives, parental investment in and attitudes towards education likely play a fundamental role in shaping the views on schooling of children experiencing homelessness (Buckner 2008; Wright 2014). We believe that understanding the types of supports parents need to either support their child's education or shift their views regarding their child's education and aligning these educational supports with parent needs and worldviews, is essential to positive educational outcomes for young students experiencing homelessness. Parents are necessary stakeholders in their children's lives, educational and otherwise, and thus play an essential role in shaping their children's values around education (Kilmer et al. 2012). Given the foundational role parents play, we believe it is crucial to understand parent perspectives and to view parents as resources in supporting their child's education.

\section{Research Design}

This qualitative study focused on the ways in which parents experiencing homelessness reportedly conceptualized parenting and their children's educational lives. An inductive approach (Corbin et al. 2015) was necessary given the exploratory nature of these investigations, the intention to understand how individuals make meaning of homelessness and their parenting experiences, and the limited work on which to build in this area. Though this study is limited by its reliance on self-report data, the approach utilized is appropriate given the intention to understand how individuals perceive and understand their experiences parenting while homeless.

\section{Participants and Context}

We conducted semi-structured interviews with 17 parents/guardians (two males and fifteen females), each of whom was currently experiencing homelessness and had a child enrolled in either Head Start or a local publiclyfunded preschool program. Head Start is a program of the United States Department of Health and Human Services that provides comprehensive early childhood education, health, nutrition, and parent involvement services to lowincome children and families. Unfortunately, Head Start participation is conditional upon available funding, so not all eligible children are able to enroll in the present community. Consequently, some children unable to participate 
in Head Start programming elect to attend in early learning opportunities funded by the local school district. In this study, participants enrolled in Head Start 4 K programming attend $8 \mathrm{~h}$ per day for 5 days per week. In contrast, participants served by the locally-funded program attend $4 \mathrm{~h}$ per day for five days per week, and do not receive comprehensive health, nutrition, and family support services. These differences will be important subsequently, when reviewing findings from this investigation.

Participants were recruited through letters delivered to them by Head Start Family Support staff and/or classroom teachers during school drop-off or regularly scheduled check-in appointments. Participants ranged in age from 20 years-old to 55 years-old. 16 participants identified as parents and one identified as a grandparent. The number of children being cared for by participants ranged from 1 to 7 , with the average being 3.4 children per household. $52 \%$ of participants self-identified as African-American, $24 \%$ as Latino/a, $12 \%$ as White, and $12 \%$ as being of mixed racial heritage. Forty-seven percent of participants graduated from high school, $47 \%$ completed some high school education, and $6 \%$ had completed some work towards a college degree. Roughly one-third of participants were living in shelters, one-third in transitional housing, and one-third in doubled-up accommodations at the time their interviews were conducted.

This study was implemented in a small Mid-Western city. Mirroring almost exactly the national averages for homelessness, roughly 1 in $204 \mathrm{~K}$ students are identified as homeless in this city. At the time of data collection in 2018-2019, roughly 550 children under the age of 6 were experiencing homelessness in the community. In 2015 alone, the number of families experiencing homelessness who sought Head Start services increased 188\% from 26 to 75 children. Structural elements, including a shortage of subsidized housing and shelter space, relatively high rental rate, relatively few low-cost housing options, and competition with students for available units, combined to make it extremely difficult for economically-fragile familes to find and afford housing.

The purpose of the interviews was to determine participant perspectives on preschool programming and how well it was meeting the needs of their children and family. Participation was voluntary, and volunteers received a $\$ 20$ Target gift card at the completion of their interview. Interviews lasted approximately $60 \mathrm{~min}$ and were conducted in a private meeting space by the first author or one of two graduate students trained in qualitative interviewing. Interviews were audio-recorded and transcribed to facilitate data analysis. Transcripts were then cross-checked by one of the authors to ensure accuracy. All data has been de-identified and pseudonyms were assigned to ensure participant confidentiality. Data was coded using both open and theoretical coding strategies and used matrices to facilitate cross-case/ thematic analysis.

\section{Data Analysis}

Analysis was conducted by the authors. The first author is a university professor who teaches graduate level courses in qualitative research methodologies. The second and third authors are graduate students who have been mentored by the first author in qualitative research methodology. We used an iterative approach for analysis that involved the concurrent processes of coding, developing data displays, and writing analytic memos. We began with the use of open coding to identify emergent themes and concepts. Sample open codes included: "tiger mom", "depression", "high hopes", and "it's hard out here". Next, we utilized theoretical codes drawn from the relevant research literature and our conceptual framework. Sample theoretical codes included: "benefits to children", "attitudes about education", "experiences with teachers", and "parenting challenges".

We used data displays, organized in the form of matrices, to help summarize data, categorize codes, and to identify/ clarify emergent themes (Miles and Huberman 1994). For example, we used comparative matrix displays corresponding to each main research question, which allowed us to compare and contrast participant responses on each respective dimension. In addition, we drafted analytic memos throughout data collection and analysis in order to capture insights and support data interpretation (Charmaz 2008; Corbin et al. 2015).

To enhance the reliability of the analytic process, we used several strategies. First, each transcript was coded by at least two people. Throughout data analysis, we used the process of consensus, which required that all members of the research team agreed on the meanings of codes, interpretations, and findings (Hill et al. 2005; Jarrett and Coba-Rodriguez 2018). To guard against reactivity and internal bias, we shared emergent themes and preliminary interpretations with colleagues through a process of peer de-briefing (Lincoln and Guba 1985). Finally, when unsure of participants' meanings, we utilized member checks to ensure that our analyses were valid representations of participant perspectives (Birt et al. 2016).

\section{Findings}

\section{Pathways to Homelessness}

Participants shared multiple pathways to becoming homeless/highly mobile. A majority of participants explained that they became homeless after losing employment and/or experiencing evictions and indicated that it has proven even more 
challenging to receive approval from housing rental agencies with an eviction on their records. Of those having received an eviction, all reported applying for housing multiple times, only to be rejected because of their rental history. All of these participants indicated that a lack of affordable housing and high rental rates in the community, as well as housing policies which allow landlords to discriminate against applicants with evictions, has contributed to the time that they have remained homeless.

Several other participants described "fleeing" [a large Midwestern City]. One shared that after witnessing a driveby shooting in her neighborhood, she packed her family's clothing, loaded her children in the car, and drove to their present city, saying "I knew that if I didn't get them out of there right away, they could be dead. That neighborhood was not safe." Another participant shared that she moved her family to their current location after losing everything in an apartment fire, explaining, "All of us were afraid in the neighborhood anyway, so we took the fire as a chance for a fresh start. We were going to have to start over somewhere, figured it should be a safer place."

Experiences of domestic violence were another major pathway to homelessness among participants in this study. Half of participants shared that experiences of abuse had led them to flee stable housing with their children. Two other participants shared that struggles with addiction had contributed to their becoming homeless, while one participant discussed difficulty finding housing after transitioning from incarceration.

In addition to those challenges mentioned previously, participants indicated that a lack of family support, mental health challenges, low wage jobs, and few supports in times of need also contributed to their becoming and/or remaining homeless. Over two-thirds of participants indicated that they have experienced traumatic events, including those contributing to the reasons they became homeless and occurring while enduring homelessness.

\section{Navigating Stigma Related to Homelessness}

While participants generally reported feeling supported by the local $4 \mathrm{~K}$ program, they shared concerns about how their housing status impacts the way they are viewed and how their children may be treated. Several parents reported concerns that teachers do not understand the challenges their children are facing and develop a negative perspective of them. One parent explained that teachers must understand that, "If homeless, the child's gonna not be ready for school the next day. Gonna have an attitude, gonna show out... Maybe won't make it to school because there's no transportation." Rather than viewing their children as "bad" or parents as "not good," one participant represented what we heard repeatedly from parents when she said, "Teacher need to know that people who are homeless are doing the best they can, they are not trying to make things harder for anyone."

Five African-American participants indicated concerns that their children were going to be labeled as "Special Needs" or identified as "Special Education," because of the challenges their children were demonstrating as a result of being homeless and/or experiencing trauma. One mother said, "I don't want my boy labeled, because everyone is labeling black boys. The teachers keep asking me to sign the papers, but I don't think they are helping him, they just want to blame him." Another parent said, "He's homeless, he ain't a bad kid."

Multiple participants indicated that they had been unwilling to share their housing status with teachers/program staff because of concerns about how they would be perceived/ or fears that they might be reported to Child Protective Services. One parent said, "People should be more open about homelessness and not be scared that CPS will take your children... there are times I should have reach out for help, but did not because I was afraid." Also, participants reported concerns about sharing scary/traumatizing experiences endured by children because of similar child protective concerns. One parent said, "My [child] saw me beaten and I know it bothers him, but I can't tell his teacher because I don't want to lose him." Another shared, "He sees some scary things in the shelter and on the streets, and I don't really know what to say to him, but I don't think I can ask the school because they might take him away." A mother indicated feeling "overwhelmed and like I don't know what to do.... My [mental health problem] sometimes freaks me out and I know it's not good for my daughter, but who can I tell?".

Most participants indicated that they want teachers and others to know that they have high expectations for their children, are trying to better themselves, and want things to be different. Multiple participants reported being enrolled in educational programming, including job training programs, while others indicated that they are "in therapy and trying to get help" so that they can be the parents that their children need. Multiple parents said something similar to this participant who offered, "I want my daughter to be in school for a long time, get a good education, be a normal kid." Another said, "I want to have a nice job, own a little house that is safe, stable, and a home for the kids. I just want to cook dinner for them."

\section{Perceptions of $4 \mathrm{~K}$ and Attitudes About Education}

Without exception, interview participants reported valuing education and indicated they allowed their children to participate in $4 \mathrm{~K}$ because it is good for their children's academic and social-emotional development. In describing the 
benefits of the program, participants said: "allows children to socialize," "teaches them things," "helps children interact with authority figures that are not parents," "improves language," "they get to play," "gives them a safe place to be during the day," and "teaches children to be independent from parents." They appreciated that "teachers care," "my child talks more," "helps them like learning," and "[my child] is learning letters and how to write her name." These parents/guardians also appreciated that their children received healthy meals.

In addition to these child benefits, participants indicated that $4 \mathrm{~K}$ is a valuable social support for themselves. Over two-thirds of participants valued $4 \mathrm{~K}$ because it allows them time to work/seek employment, participate in job training, or schedule other appointments. Several parents talked about the importance of having a mental break from parenting, indicating that the respite allows them to be more responsive to their children when they are not in school.

\section{Program Structures}

Of the study participants, 12 reported participating in a full-day Head Start program that is also subsidized by local $4 \mathrm{~K}$ funding. All of these parents reported that the full-day program model is their most important resource/social support. Of these parents, 10 said that they would not be able to enroll their child in $4 \mathrm{~K}$ if the program was only half-day. Of those participating in half-day programs, all said that their preference would be for full-day participation. These participants reported that half-day programs did not allow them time to get their child to school, travel to work, work, and then reverse the process. Multiple participants shared their frustration at having to decide between their child's education and working. Several parents shared comments like, "I cannot work much because my child is in $4 \mathrm{k}$."

Participants indicate that transportation assistance is the most important support they receive in reducing barriers to participation in PreK programming. Most participants reported that their children receive transportation from their home/residence to the program, and all but two participants indicated that they would be unable to participate in the program without such assistance. For parents with automobiles, they said that gas cards/vouchers are extremely beneficial. In describing how things would work without transportation to the program, three participants said that they would need to switch buses multiple times and spend over an hour each way to get their child to school. For children in half day programs, parents said that they would barely have time to get home before needing to return to collect their child, much less work, seek employment, participate in job training, or to complete other appointments.
Participants indicated the school social workers/case managers also provide critical support. Participants described receiving support in making and attending children's medical appointments, receiving referrals to housing and other type of social service agencies, benefiting from home visits and parenting advice, and feeling like there was someone there to "listen to them and care how they are doing."

Though participants typically reported positive relationships with teachers, roughly half said they had very little/ minimal contact with children's classroom teacher. These participants indicate that interactions with teachers typically focus on attendance/behavioral issues, etc. Approximately one-third of participants reported positive interactions/ more engaged relationships with teachers. These participants frequently said, "I love her!" When asked to describe the type of supports these teachers provided, participants responded, "She is all about the kids-I love her demeanor and patience", "She provides helpful suggestions for parenting", "She asks how I'm doing and values my opinion", "I feel like I can talk to her about anything and she won't judge". These teachers were also described as, "Communicating frequently", "Responsive to emails and writes often", and "Treats everyone the same". When asked what they valued about the teachers' interactions with their child, roughly half of participants said something like, "She is firm," or, "She is good at making my child behave," while the other half said, "She is kind and patient," or, "She seems like a nice person."

When asked about their contact with other families, all but two of the participants indicated that they have very little contact with other families in their children's program. They also said that it was not important to them, with some noting, "I'm not a people person," "I want to focus on doing my thing. I don't need more people in my business," or, "I'm not in this for all that." However, two participants indicated that their children attended the program with relatives or children who they knew previously from time spent living in a shelter. These participants appreciated that the program helps them stay connected and maintain these important relationships in the midst of other housing/life transitions. One participant did indicate that she would appreciate receiving a family directory so that she might connect with other families.

Participants had mixed experiences with enrollment. Two-thirds reported that it was relatively easy, indicating they were guided through the enrollment process by case workers or other service providers. For those who found their way to the programs independently, the process was described as "difficult" or "too much paperwork."

\section{Suggestions for Strengthening}

When asked what suggestions they had for strengthening, participants overwhelmingly stated that they would like to 
lengthen program hours and provide more aftercare options. Participants also frequently called for improvements to the transportation system. Participants' comments focused on frequent delays and suggested more predictable bus schedules and friendlier bus drivers. Several participants indicated that transportation is occasionally cancelled unexpectedly, and that this creates challenges with work, etc. Five participants also expressed concerns about the amount and quality of food provided, indicating that children should be fed more at school and provided with healthier "home like" meal options. Participants indicated that for children living in the shelter or on the streets, almost "every meal is microwaved or fast food." These parents view schools as their children's best option for a healthy meal. Other suggestions include more support for enrollment and more interactions with teachers.

\section{Discussion and Implications}

Overall, participants communicated an appreciation for their child(ren)'s education, concerns about stigma surrounding homelessness, and thoughts around the most beneficial aspects of the $4 \mathrm{~K}$ program as well as ways the program could better meet the needs of families.

One primary theme that emerged was the varied pathways to homelessness experienced by families. Unemployment and history of evictions were the most significant barriers to obtaining secure housing for families, as landlords are able to use these stressors to discriminate against families applying for housing. High costs and low availability of housing were also noted as obstacles, suggesting families experiencing homeless face multiple interconnecting systemic barriers in attempting to secure stable housing. Many of these barriers are cyclical: parents who have lost their jobs cannot afford high housing rates, are discriminated against for their unemployment status, and are denied housing which could potentially provide the stability needed to assist parents in seeking employment. This highlights the necessity of housing policies that create affordable housing and prevent discrimination against families who are already broadly marginalized.

Further issues that resulted in high mobility and/or homelessness for families included violence in the community, domestic violence, lack of community and family support, mental health challenges and poverty. Several families described their migration to the small city in which this study was implemented as a means of escaping community violence in a much larger city. In a sample of elementary school children from the larger city mentioned by participants in this study, more than one in four children have witnessed life-threatening community violence, including shootings and stabbings (Bell and Jenkins 1993). Children who reported witnessing more frequent violence were more likely to engage in fighting.

In addition to exposure to community violence, half of the parents interviewed reported experiencing homelessness as a result of escaping domestic violence at home. Witnessing and/or experiencing family abuse and violence can impact emotional self-regulation, mental health and externalizing and internalizing behavior problems for youth (Cicchetti and Toth 2005; Egeland et al. 2002). Violence in the home has been associated with PTSD symptoms and aggressive behavior in youth, while exposure to community violence is correlated with internalizing and externalizing symptoms in youth (Mohammad et al. 2015). Clearly, exposure to any kind of violence is related to poor outcomes for children. Parents from communities characterized by this violence are likely aware of these outcomes and feel compelled to leave violent situations to protect themselves and their children, even if doing so destabilizes their living conditions and results in high mobility. The effects of violence are further highlighted by the fact that children living with various demographic risk factors-including poverty, racial and ethnic minority status, etc. - are at higher risk for more frequent exposure to violence. These findings indicate that effective preschool programming would be informed by an awareness of trauma and community violence, and that educational and social supports would be trauma-informed. For example, using mindfulness strategies, trauma and culturally-responsive curricular materials, and providing access to high quality mental health supports would be beneficial elements for families and children experiencing homelessness.

Relatedly, many parents commented on the stigma surrounding homelessness, with several describing the compounded effects of racial and homelessness-related stigma. While some individuals may hold sympathetic views of families experiencing homelessness, negative views are more common in the public, who may view homelessness as the fault of the individual's laziness and poor choices (Link et al. 1995; Meanwell 2012). Individuals experiencing homelessness are deeply aware of these negative perceptions and respond by trying to distance themselves from others who may hold these stigmatizing views, embrace seeing themselves as being from the "street," or fictionalizing past, present, and future experiences (Roschelle and Kaufman 2004; Snow and Anderson 1987; Snow and Mulcahy 2001). Parents described experiences of teachers and school personnel as viewing themselves and their children as bad and were frustrated that teachers did not seem to understand that homelessness necessarily impacts their children's' emotions and behavior. If this stigma is perceived by parents, children may also pick up the differential treatment they receive compared to their peers, which may further exacerbate emotional and behavioral challenges in school for children experiencing homelessness. 
Further, several parents commented on their fears that their children may be labeled or segregated due to stigmatizing and discriminatory views based on their children's housing instability and racial and ethnic background. These fears are more than valid, as research has demonstrated race is a predictor of differential diagnosis among youth, with youth of color more likely to be diagnosed with disruptive behavior disorders and learning disabilities compared to white youth (Nguyen et al. 2007; Shifrer et al. 2011). Parents are rightly concerned that their children will be doubly targeted as requiring special needs based both on their ethnic identities and housing status. These findings suggest that efforts to support teachers and staff in recognizing and reducing bias would be critical to developing a supportive preschool environment for children and families experiencing homelessness. Likewise, preschool programs should be proactive in reaching out to families in a positive and affirming way in order to earn the trust and sustain an open line of communication with parents experiencing homelessness.

Regarding the $4 \mathrm{~K}$ program itself, parents valued the program for providing their children with a well-rounded education, opportunities for social and emotional development, and relationships with caring, compassionate teachers. Parents were also appreciative of the program facilitating time in their day to seek employment, attend to other responsibilities, and rest so that they could be more focused on their children when they returned from school. Many parents emphasized the importance of a full-day (as opposed to half-day) program, social workers and case workers, and transportation in making the $4 \mathrm{~K}$ program work for them. As programs like this continue to expand in other districts, maintaining these core supports will be essential. Parents also identified areas where the program could improve, such as by adding after school programming for students, increasing the frequency and reliability of buses, and improving the nutritional value of the meals that their children are served in school.

Parents were involved enough in their child's education to see both the benefits and room for change within $4 \mathrm{~K}$. This involvement is critical to positive child outcomes, as parental involvement in a child's education is associated positively with achievement outcomes, positive self-concept, classroom behavior, expectations for the future, and motivation (Cotton and Wikelund 1989). While homelessness introduces many challenges for families, especially families with small children, housing instability did not appear to impact these parents' concerns about their children's wellbeing or futures.

\section{Conclusion}

Families with children constitute a large percentage of the overall homeless population (Guarino and Bassuk 2010). This reality raises the question of how issues surrounding housing stability impact children's development, their capacity to attend and benefit from an education, and their ability to form and maintain stable relationships. Overwhelmingly, systemic factors including poverty, unjust housing laws, community and domestic violence, and varying degrees of stigma and oppression contribute to the rise in homelessness and the impact of high mobility on young children.

Overall, findings from this study suggest that high-quality preschool experiences which are informed by an understanding of homelessness and its potential implications may play an important role in buffering children and families experiencing homelessness from its overwhelming consequences. These participants reported gratitude for their $4 \mathrm{~K}$ program and described the positive impacts that $4 \mathrm{~K}$ programming had on their children and family's development. Their perspectives suggest that holistic educational programming that considers the needs of the individual child and the family as a system, help parents support their children in schools. Providing transportation to and from school, meals for children while in school, and supportive teachers and staff can be beneficial to children and families. As an essential first step, findings from this study suggest that supporting staff in recognizing their own biases about families experiencing homelessness is central to developing a supportive organizational climate. Moreover, our findings underscore a call to action for schools and districts to act against the systemic forces oppressing families experiencing homelessness by intentionally centering their programmatic approach around the needs of these most vulnerable children and families.

\section{References}

Anooshian, L. J. (2005). Violence and aggression in the lives of homeless children. Journal of Family Violence, 20(6), 373-387. https ://doi.org/10.1007/s10896-005-7799-3.

Bassuk, E. L. (2010). Ending child homelessness in America: Ending child homelessness. American Journal of Orthopsychiatry, 80(4), 496-504. https://doi.org/10.1111/j.1939-0025.2010.01052.x.

Bassuk, E. L., Richard, M. K., \& Tsertsvadze, A. (2015). The prevalence of mental illness in homeless children: a systematic review and meta-analysis. Journal of the American Academy of Child \& Adolescent Psychiatry, 54(2), 86-96.

Bassuk, E. L., Weinreb, L. F., Buckner, J. C., Browne, A., Salomon, A., \& Bassuk, S. S. (1996). The characteristics and needs of sheltered homeless and low-income housed mothers. JAMA, 276(8), 640. https://doi.org/10.1001/jama.1996.03540080062031.

Bell, C. C., \& Jenkins, E. J. (1993). Community violence and children on Chicago's southside. Psychiatry, 56(1), 46-54. 
Birt, L., Scott, S., Cavers, D., Campbell, C., \& Walter, F. (2016). Member checking: a tool to enhance trustworthiness or merely a nod to validation? Qualitative health research, 26(13), 1802-1811.

Buckner, J. C. (2008). Understanding the impact of homelessness on children: challenges and future research directions. American Behavioral Scientist, 51(6), 721-736.

Casey, E. C., Shlafer, R. J., \& Masten, A. S. (2015). Parental incarceration as a risk factor for children in homeless families. Family Relations, 64(4), 490-504. https://doi.org/10.1111/fare.12155.

Charmaz, K. (2008). Grounded theory as an emergent method. In S. N. Hesse-Biber \& P. Leavy (Eds.), Handbook of emergent methods (pp. 155-170). New York: The Guilford Press.

Chavkin, N. F., \& Williams, D. L. (1989). Low-income parents' attitudes toward parent involvement in education. Journal of Sociology and Social Welfare, 16(3), 17-28.

Children's Defense Fund (2017). The State of America's Children 2017. Retrieved from https://www.childrensdefense.org/wpcontent/uploads/2018/06/2017-soac.pdf.

Child Trends. (2019). Children and Youth Experiencing Homelessness. Retrieved from https://www.childtrends.org/indicators/ homeless-children-and-youth.

Cicchetti, D., \& Toth, S. L. (2005). Child maltreatment. Annual Review of Clinical Psychology, 1, 409-438.

Corbin, J., Strauss, A. L., \& Strauss, A. (2015). Basics of qualitative research. London: Sage.

Cotton, K., \& Wikelund, K. R. (1989). Parent involvement in education. School Improvement Research Series, 6(3), 17-23.

Cowal, K., Shinn, M., Weitzman, B. C., Stojanovic, D., \& Labay, L. (2002). Mother-child separations among homeless and lowincome mothers: a five-year birth cohort study. Journal of Sociology \& Social Welfare, 30, 79-95.

Cutuli, J. J., Desjardins, C. D., Herbers, J. E., Long, J. D., Heistad, D., Chan, C.-K., et al. (2013). Academic achievement trajectories of homeless and highly mobile students: resilience in the context of chronic and acute risk. Child Development, 84(3), 841-857. https://doi.org/10.1111/cdev.12013.

Dail, P. W. (1990). The psychosocial context of homeless mothers with young children: program and policy implications. Child Welfare: Journal of Policy, Practice, and Program, 69(4), 291-308.

Delpit, L. (1995). Other people's children: cultural conflict in the classroom. New York: The New Press.

Egeland, B., Yates, T., Appleyard, K., \& Van Dulmen, M. (2002). The long-term consequences of maltreatment in the early years: a developmental pathway model to antisocial behavior. Children's Services: Social policy, Research, and Practice, 5(4), 249-260.

Fantuzzo, J., LeBoeuf, W., Brumley, B., \& Perlman, S. (2013). A population-based inquiry of homeless episode characteristics and early educational well-being. Children and Youth Services Review, 35(6), 966-972. https://doi.org/10.1016/j.childyouth.2013.02.016.

Guarino, K., \& Bassuk, E. (2010). Working with families experiencing homelessness: understanding trauma and its impact. Zero to Three, 30(3), 11-20.

Herbers, J. E., Cutuli, J. J., Lafavor, T. L., Vrieze, D., Leibel, C., Obradović, J., et al. (2011). Direct and indirect effects of parenting on the academic functioning of young homeless children. Early Education \& Development, 22(1), 77-104. https://doi. org/10.1080/10409280903507261.

Hill, C. E., Knox, S., Thompson, B. J., Williams, E. N., Hess, S. A., \& Ladany, N. (2005). Consensual qualitative research: an update. Journal of Counseling Psychology, 52(2), 196-205. https://doi. org/10.1037/0022-0167.52.2.196.

Jarrett, R. L., \& Coba-Rodriguez, S. (2018). How African American mothers from urban, low-income backgrounds support their children's kindergarten transition: qualitative findings. Early Childhood Education Journal, 46(4), 435-444.
Joint Center for Housing Studies. (2020). America's Rental Housing 2020. Resource document. https://www.jchs.harvard.edu/ameri cas-rental-housing-2020

Kelly, J. F., Buehlman, K., \& Caldwell, K. (2000). Training personnel to promote quality parent-child interaction in families who are homeless. Topics in Early Childhood Special Education, 20(3), 174-185. https://doi.org/10.1177/027112140002000306.

Kilmer, R. P., Cook, J. R., Crusto, C., Strater, K. P., \& Haber, M. G. (2012). Understanding the ecology and development of children and families experiencing homelessness: implications for practice, supportive services, and policy. American Journal of Orthopsychiatry, 82(3), 389-401. https://doi.org/10.111 1/j.1939-0025.2012.01160.x.

Link, B. G., Schwartz, S., Moore, R., Phelan, J., Struening, E., Stueve, A., et al. (1995). Public knowledge, attitudes, and beliefs about homeless people: evidence for compassion fatigue? American Journal of Community Psychology, 23(4), $533-555$.

Long, H \& Van Dam, A. (2020). U.S. unemployment rate soars to 14.7 percent, the worst since the Depression era. Resource document. The Washington Post. https://www.washingtonpost.com/ business/2020/05/08/april-2020-jobs-report/

Masten, A. S. (2012). Risk and resilience in the educational success of homeless and highly mobile children: introduction to the special section. Educational Researcher, 41(9), 363-365.

Meanwell, E. (2012). Experiencing homelessness: a review of recent literature. Sociology Compass, 6(1), 72-85.

Miles, M. B., \& Huberman, M. (1994). Qualitative data analysis: an expanded sourcebook (2nd ed.). London: Sage Publications Inc.

Miller, P. M. (2011). A critical analysis of the research on student homelessness. Review of Educational Research, 81(3), 308-337. https://doi.org/10.3102/0034654311415120.

Mohammad, E. T., Shapiro, E. R., Wainwright, L. D., \& Carter, A. S. (2015). Impacts of family and community violence exposure on child coping and mental health. Journal of Abnormal Child Psychology, 43(2), 203-215.

National Alliance to End Homelessness (2019). State of homelessness. Resource document. https://endhomelessness.org/homel essness-in-america/homelessness-statistics/state-of-homelessne ss-report/

Nguyen, L., Huang, N., Arganza, G. F., \& Liao, Q. (2007). The influence of race and ethnicity on psychiatric diagnoses and clinical characteristics of children and adolescents in children's services. Cultural Diversity and Ethnic Minority Psychology, 13(1), 18-25.

Powers-Costello, E., \& Swick, K. J. (2008). Exploring the dynamics of teacher perceptions of homeless children and families during the early years. Early Childhood Education Journal, 36(3), 241-245. https://doi.org/10.1007/s10643-008-0249-0.

Roschelle, A. R., \& Kaufman, P. (2004). Fitting in and fighting back: stigma management strategies among homeless kids. Symbolic Interaction, 27(1), 23-46.

Shifrer, D., Muller, C., \& Callahan, R. (2011). Disproportionality and learning disabilities: parsing apart race, socioeconomic status, and language. Journal of Learning Disabilities, 44(3), 246-257.

Snow, D. A., \& Anderson, L. (1987). Identity work among the homeless: the verbal construction and avowal of personal identities. American Journal of Sociology, 92(6), 1336-1371.

Snow, D. A., \& Mulcahy, M. (2001). Space, politics, and the survival strategies of the homeless. American Behavioral Scientist, 45(1), 149-169.

Stronge, J., \& Reed-Victor, E. (2000). Educating homeless students: promising practices. Larchmont, New York: Eye on Education.

Swick, K. J. (2009). Strengthening homeless parents with young children through meaningful parent education and support. Early Childhood Education Journal, 36(4), 327-332. 
The U.S. Department of Housing and Urban Development, Office of Community Planning and Development (2018). The 2018 Annual Homeless Assessment Report (AHAR) to Congress. Resource document. https://www.wpr.org/sites/default/files/2018-ahar-part1-compressed.pdf.

United States Interagency Council on Homelessness (2018, September). Homelessness in America: Focus on Families with Children. Resource document. https://www.usich.gov/resources/uploads/ asset_library/Homeslessness_in_America_Families_with_Child ren.pdf

Weinreb, L., Goldberg, R., Bassuk, E., \& Perloff, J. (1998). Determinants of health and service use patterns in homeless and lowincome housed children. Pediatrics, 102(3), 554-562.

Wright, T. (2007). On Jorge becoming a boy: A counselor's perspective. Harvard Educational Review, 75(2), 164-186.

Wright, T. (2010). Learning to laugh: A portrait of risk and resilience in early childhood. Harvard Educational Review, 80(4), 444-463.

Wright, T. (2013). "I keep me safe." Risk and resilience in children with messy lives. Phi Delta Kappan, 95(2), 39-43.

Wright, T. (2014). Too scared to learn: Teaching young children who have experienced trauma. Young Children, 69(5), 88-93.
Wright, T. (2018). Beauty in the struggle: Poetry found in the lives of mothers experiencing homelessness. Anthropology and Education Quarterly, 49(4), 462-468.

Wright, T., Taub, A., Fetter, A., \& Shumpert, J. (2017). MMSD 4K: Pathways to Resilience for children and families experiencing homelessness. Report for Madison Metropolitan School District.

Wright, T., Nankin, I., Boonstra, K., \& Blair, E. L. (2019). Changing through relationships and reflection: An exploratory investigation of pre-service teachers' perceptions of young children experiencing homelessness. Early Childhood Education Journal, 47(3), 297-308.

Yang, S., \& Shin, C. S. (2008). Parental attitudes towards education: what matters for children's well-being? Children and Youth Services Review, 30(11), 1328-1335.

Zaveri, M. (2020). Number of homeless students rises to new high, report says. Resource Document. The New York Times. https ://www.nytimes.com/2020/02/03/us/Homeless-students-publi c-schools.html

Publisher's Note Springer Nature remains neutral with regard to jurisdictional claims in published maps and institutional affiliations. 